\title{
PRAKTEK PEMBERIAN ASI EKSLUSIF PADA IBU PEKERJA DI DESA BATUSUYA KABUPATEN DONGGALA
}

\author{
PRACTICE OF EXCLUSIVE BREAST FEEDING FOR WORKING MOTHERS IN BATUSUYA \\ VILLAGE DONGGALA DISTRICT
}

\author{
Adhyanti, Dwi Erma Kusumawati, Riska Afifah* \\ Poltekkes Kemenkes palu \\ (riskaafifah3008@gmail.com, 082271449500)
}

\begin{abstract}
ABSTRAK
Air susu ibu (ASI) adalah sumber nutrisi yang ideal dan makanan yang paling aman bagi bayi selama 0-6 bulan kehidupan. Data Riset Kesehatan Dasar (Riskesdas) tahun 2018 diketahui proporsi bayi usia 0-6 bulan yang mendapatkan ASI ekslusif adalah 74,5\%, sedangkan yang tidak mendapatkan ASI ekslusif sebesar 25,5\%. Tujuan penelitian ini untuk mengetahui gambaran praktek pemberian ASI ekslusif pada ibu pekerja di Desa Batusuya Kecamatan Sindue Tumbusbora Kabupaten Donggala. Jenis penelitian ini merupakan penelitian deskriptif. Populasi dari penelitian ini adalah seluruh ibu pekerja yang mempunyai balita usia 0-6 bulan. Sampel dalam penelitian ini berjumlah 60 orang. Analisis data dilakukan secara univariat. Hasil penelitian menunjukan bahwa 51\% anak dari ibu-ibu pekerja tidak diberikan ASI Eksklusif dan 56,7\% ibu balita bekerja sebagai wiraswasta. Beberapa alasan tidak diberikan ASI eksklusif adalah ibu tidak dapat membawa anak ketempat kerja dan ibu tidak tahu cara menyimpan ASI di freezer. Kesimpulan penelitian ini, sebagian besar ibu tidak memberikan ASI Eksklusif. Kepada ibu pekerja disarankan untuk lebih memperhatikan pentingnya ASI eksklusif.
\end{abstract}

Kata Kunci : ASI Eksklusif, Ibu Pekerja

\section{ABSTRACT}

Breast milk (ASI) is an ideal source of nutrition and the safest food for babies for 0-6 months of life. Basic Health Research Data (Riskesdas) in 2018 shows that the proportion of infants aged 0 6 months who receive exclusive breastfeeding is 74.5\%, while those who do not receive exclusive breastfeeding are $25.5 \%$. The purpose of this study was to describe the practice of exclusive breastfeeding for working mothers in Batusuya Village, Sindue Tumbusbora District, Donggala Regency. This type of research is a descriptive study. The population of this study were all working mothers who have children aged 0-6 months. The sample in this study amounted to 60 people. Data analysis in this study used univariate analysis. The results showed that $51 \%$ of children were not given exclusive breastfeeding and 56.7\% of mothers under five worked as entrepreneurs. The conclusion of this study, most mothers do not give exclusive breastfeeding to their children because mothers cannot bring their children to work and mothers do not know how to store breast milk in the freezer. Special advice for working mothers to pay more attention to the importance of exclusive breastfeeding.

Keywords: Exclusive breastfeeding, working mothers 


\section{PENDAHULUAN}

Air susu ibu (ASI) adalah sumber nutrisi yang ideal dan makanan yang paling aman bagi bayi selama 0-6 bulan kehidupan. ASI melindungi bayi terhadap diare bawaan makanan melalui bahan-bahan anti-infeksi yang dikandungnya dan meminimalkan paparan dari patogen bawaan makanan. Beberapa tingkat nasional dan internasional untuk mempromosikan pemberian ASI, dan banyak bahan pendidikan yang memberikan saran pada ibu tentang cara melindungi ASI mereka dari zat kimia lainnya (misalnya, dengan meminimalkan kontak dengan peptisida, dengan menghindari konsumsi makanan yang mengandung kontaminasi dengan kadar yang tidak aman) (Andini Wirajdmadi, 2012).

Peraturan Pemerintah Republik Indonesia Nomor 33 Tahun 2017 tentang pemberian ASI ekslusif menguraikan secara spesifik bahwa pemberian ASI pada bayi harus diberikan secara ekslusif. ASI Esklusif adalah pemberian air susu ibu saja (tanpa makanan/minuman pendamping termasuk air putih maupun susu formula) selama 6 bulan, untuk kemudian diteruskan hingga 2 tahun atau lebih, dan setelah enam bulan baru didampingi dengan makanan/minuman pendamping ASI (MP-ASI) sesuai perkembangan pencernaan anak. (Purwanti, 2012). Bayi baru lahir perlu mendapat perawatan yang optimal sejak dini, termasuk pemberian makanan yang ideal. Tidak ada satupun makanan yang ideal untuk bayi selain ASI (Mulyani 2013).

Pemberian ASI kepada bayi merupakan suatu interaksi kompleks antara kebutuhan gizi bayi dan fisiologi ibu. Menyusui yang benar akan memberikan manfaat dalam perkembangan anak dan ekonomi. Namun, selain itu memberikan zat gizi seimbang optimal dalam bentuk yang sesuai dengan perkembangan bayi, ASI juga mengompensasi kemampuan pencernaan yang inparatur dan kerentanan status imun bayi (Kemenkes, 2013). ASI sangat baik baik bagi bayi karena mengandung zat-zat yang sangat penting yang dapat membentuk daya tahan tubuh (Muryunani, 2012).

Bayi yang tidak diberikan ASI ekslusif akan berdampak pada kesehatan dan status gizi bayi. Menurut Ni'mah dan Nadhiroh (2015). bahwa balita yang tidak mendapatkan ASI Eksklusif berisiko 4 kali mengalami stunting dibandingkan dengan balita yang mendapatkan ASI ekslusif. Menurut Setyarini dan Mexitalia (2015) bahwa anak yang mengkonsumsi ASI eksklusif sebagian besar $(76,2 \%)$ tidak memiliki masalah mental emosional, sedangkan anak yang tidak mengkonsumsi ASI eksklusif cenderung memiliki masalah mental emosional (64,3\%).

Hasil Riset Riskesdas Dasar (2018) menunjukan proporsi bayi usia 0-6 bulan yang mendapatkan ASI ekslusif adalah 74,5\%, sedangkan yang tidak mendapatkan ASI ekslusif sebesar 25,5\%. Poroporsi ASI ekslusif lebih 
tinggi terdapat di daerah pedesaan dibandingkan di perkotaan, yang mana di pedesaan sebesar $76,6 \%$, sedangkan diperkotaan sebesar $72,7 \%$ (Kemenkes, 2018). Di Kabupaten Donggala (2019) dari 1.991 bayi, hanya 1.288 bayi $(64,7 \%)$ yang mendapat ASI ekslusif, sedangkan bayi yang tidak mendapat ASI ekslusif sebanyak 703 bayi (35,4\%) (Dinkes Donggala, 2019).

Data pada tahun 2019 di Puskesmas Batusuya menunjukan bahwa dari 82 bayi, hanya 25 bayi (30,5\%) yang mendapatkan ASI ekslusif, sedangkan bayi yang tidak mendapatkan ASI ekslusif sebanyak 57 bayi $(69,57 \%)$ (Puskesmas Batusuya, 2019). Tujuan penelitian ini adalah mengetahui gambaran praktek ASI ekslusif pada ibu di Desa Batusuya Kecamatan Sindue Tumbusbora Kabupaten Donggala.

\section{METODE PENELITIAN}

Jenis penelitian ini merupakan penelitian deskriptif yaitu penelitian yang dilakukan untuk melihat gambaran praktek pemberian ASI ekslusif pada ibu pekerja di Desa Batusuya Kecamatan Sindue Tumbusabora Donggala. Penelitian dilaksanakan pada bulan Agustus 2020. Populasi dari penelitian ini adalah seluruh ibu pekerja yang mempunyai balita usia 0-6 bulan di Desa Batusuya Kecamatan Sindue Tumbusabora Kabupaten Donggala yang berjumlah 60 orang sekaligus sebagai responden atau sampel diperoleh dari hasil observasi langsung dengan teknik pengambilan sampel menggunakan metode accidental sampling. Analisis yang digunakan adalah analisis univariat dan disajikan dalam bentuk tabel dan narasi.

\section{HASIL}

\section{Karakteristik Responden}

Jumlah responden yang berhasil dikumpulkan datanya adalah 60 ibu pekerja. Hasil analisis karakteristik ibu balita dapat dilihat pada tabel berikut :

Tabel 1. Gambaran distribusi umur,Besar keluarga, agama, suku, pendidikan, status perkawinan, pekerjaan suami,pekerjaan istri, kategori penghasilan keluarga

\begin{tabular}{lcc}
\hline Karakteristik & $\boldsymbol{f}$ & $\mathbf{\%}$ \\
\hline Umur & 1 & 1,7 \\
<19 Tahun & 18 & 30,0 \\
20-24 Tahun & 17 & 28,3 \\
25-29 Tahun & 14 & 23,3 \\
30-34 Tahun & 10 & 16,7 \\
40-44 Tahun & & \\
Besar Keluarga & 37 & 61,7 \\
$\quad$ 4 Orang & 23 & 38,3 \\
$\quad$ <4 Orang & & \\
Agama & & 100,0 \\
Islam & 60 & 0 \\
Kristen & 0 & \\
protestan & & 0 \\
Kristen katolik & 0 & \\
Suku & & 11,7 \\
Kaili & 7 & 88,3 \\
Bugis & 53 & \\
Pendidikan & & 16,7 \\
Tamat SD & 10 & 36,7 \\
Tamat SMP & 22 & 43,3 \\
Tamat SMA & 26 & 3,3 \\
Perguruan tinggi & 2 & \\
Status Perkawinan & & \\
Kawin & 58 & 96,7 \\
Cerai Mati & 2 & 3,3 \\
Pekerjaan Suami & & \\
Tidak bekerja & 9 & 15,0 \\
Petani & 12 & 20,0 \\
Buruh & 18 & 30,0 \\
Wiraswasta & 14 & 23,3 \\
PNS & 1 & 1,7 \\
\hline & &
\end{tabular}


Tabel 2. Gambaran distribusi umur,Besar keluarga, agama, suku, pendidikan, status perkawinan, pekerjaan suami,pekerjaan istri, kategori penghasilan keluarga (lanjutan)

\begin{tabular}{|c|c|c|}
\hline Karakteristik & $f$ & $\%$ \\
\hline \multicolumn{3}{|l|}{ Pekerjaan Suami } \\
\hline $\begin{array}{l}\text { Karyawan } \\
\text { swasta }\end{array}$ & 2 & 3,3 \\
\hline Nelayan & 3 & 5,0 \\
\hline $\begin{array}{l}\text { Tukang } \\
\text { bangunan }\end{array}$ & 1 & 1,7 \\
\hline \multicolumn{3}{|l|}{ Pekerjaan Istri } \\
\hline Petani & 14 & 23,3 \\
\hline Buruh & 2 & 3,3 \\
\hline Wiraswasta & 34 & 56,7 \\
\hline PNS & 9 & 15,0 \\
\hline \multicolumn{3}{|l|}{$\begin{array}{l}\text { Kategori } \\
\text { penghasilan } \\
\text { Keluarga }\end{array}$} \\
\hline $\begin{array}{l}\geq \mathrm{UMP} \\
\text { (Rp.2.303.711) }\end{array}$ & 25 & 41,7 \\
\hline $\begin{array}{l}<\text { UMP } \\
\text { (Rp.2.303.711) }\end{array}$ & 35 & 58,3 \\
\hline
\end{tabular}

Sumber: Data primer terolah,2020

Berdasarkan hasil analisis karakteristik umum reponden di Desa Batusuya Kecamatan Sindue Tumbusabora Kabupaten Donggala menunjukan dari 60 responden yang didapatkan sebagian besar responden berumur 20-24 tahun yaitu berjumlah 18 responden (30,0\%). Jumlah angota keluarga $\leq 4$ orang yaitu 37 responden $(61,7 \%)$. Status perkawinan menunjukan responden dengan status kawin berjumlah 58 responden $(96,7)$. Mayoritas agama islam yaitu 60 responden $(100 \%)$.

Sebagian besar responden bersuku Bugis yaitu berjumlah 53 responden (8,3\%). Pendidikan sebagian besar tamat SMA yaitu berjumlah 26 responden $(43,3)$. Suami responden sebagian besar bekerja sebagai buruh yaitu berjumlah 18 responden $(30,0)$. Pekerjaan istri sebagian besar wiraswasta yaitu berjumlah 34 responden (56,7\%). Berdasarkan upah minimum provinsi jumlah responden dengan penghasilan keluarga perbulan $<\mathrm{Rp} .2 .303 .711$ yaitu 35 responden $(58,3)$.

Selain mengumpulkan data ibu pekerja juga dikumpulkan data balita. Jumlah balita yang berhasil dikumpulkan datanya yaitu 60 orang. Karakteristik balita disajikan dalam tabel berikut :

Tabel 3 Distribusi balita berdasarkan jenis kelamin, tempat persalinan, status IMD, status pemberian kolostrum

\begin{tabular}{lcc}
\hline Karakteristik & $\boldsymbol{f}$ & $\mathbf{\%}$ \\
\hline Jenis kelamin & & \\
$\quad$ Laki-laki & 28 & 46,7 \\
$\quad$ Perempuan & 32 & 53,3 \\
Tempat & & \\
persalinan & & \\
$\quad$ Puskesmas & 45 & 75,0 \\
$\quad$ Rumah sakit & 10 & 16,7 \\
$\quad$ Rumah & 5 & 8,3 \\
Status IMD & & \\
$\quad$ Tidak & 20 & 33,3 \\
$\quad$ Ya & 40 & 66,7 \\
Status pemberian & & \\
kolostrum & & \\
$\quad$ Tidak & 17 & 28,3 \\
$\quad$ Ya & 43 & 71,7 \\
\hline Sumber: Data primer terolah,2020 & \\
& &
\end{tabular}

Berdasarkan tabel 2 menunjukan sebagian besar balita berjenis kelamin perempuan yaitu 32 orang $(53,3)$. Tempat persalinan sebagian besar di puskesmas yaitu 45 orang $(75,0)$, dan sebagian tempat persalinan di rumah yaitu 5 orang (8,3\%). Status IMD menunjukan sebagian besar dilakukan yaitu 40 orang $(66,7 \%)$, yang tidak dilakukan IMD yaitu 20 orang $(33,3 \%)$. Status pemberian kolostrum yang diberikan sebanyak 43 orang $(71,7 \%)$, dan 
yang tidak diberikan kolostrum yaitu 17 orang $(28,3 \%)$.

\section{Gambaran Variabel Utama}

a. Praktek Pemberian ASI Ekslusif adalah tindakan pemberian ASI saja tanpa tambahan makanan atau minuman lain kepada balita usia 0-6 bulan oleh ibu di Desa Batusuya. Perilaku pemberian ASI dikelompokkan menjasi 2 kategori yang memberikan ASI ekslusif dan tidak memberikan ASI ekslusif. Untuk distribusi frekuensi dapat dilihat pada tabel berikut:

Tabel 4 Pemberian ASI ekslusif pada ibu pekerja di Desa Batusuya Kecamatan Sindue Tumbusabora Kabupaten Donggala

\begin{tabular}{lcc}
\hline Pemberian ASI Eklusif & $\boldsymbol{f}$ & $\mathbf{\%}$ \\
\hline Tidak ASI Ekslusif & 51 & 85,0 \\
ASI Ekslusif & 9 & 15,0 \\
Alasan/Penyebab & & \\
Tidak Memberikan $\quad$ ASI & & \\
Ekslusif & & \\
$\quad$ ASI tidak banyak keluar & 25 & 49,0 \\
$\quad$ Payudara bagian puting lecet & 16 & 31,4 \\
Anak tidak mau menyusu & 10 & 19,6 \\
\hline
\end{tabular}

Sumber: Data primer terolah,2020

Pada tabel 3 di atas dapat dilihat kategori anak berdasarkan status pemberian ASI ekslusif sebagian besar anak tidak ASI eksklusif yaitu sebanyak 51 anak $(85,0 \%)$. Sedangkan yang ASI eksklusif hanya 9 anak $(15,0 \%)$. Alasan/penyebab ibu tidak membeikan ASI eksklusif yaitu ada 3 alasan yang pertama dikarenakan ASI tidak banyak keluar sebanyak 25 orang $(49,0 \%)$, payudaya bagian puting lecet sebanyak 16 orang $(31,4 \%)$, dan yang ketiga dikarenakan anak tidak mau menyusu sebanyak 10 orang $(19,6 \%)$.

Membawa anak ke tempat kerja adalah cara ibu balita agar membagi waktu dengan cara bekerja sambil mengurus anak. Sebagian besar responden tidak membawa anak ke tempat kerja sebanyak 51 orang $(85,0 \%)$, sedangkan yang membawa anaknya ke tempat kerja sebanyak 9 orang $(15,0 \%)$. Apabila anaknya tidak dibawa ke tempat kerja maka anaknya dijaga atau diasuh di rumah. Sebagian besar penjaga/pengasuh anak saat ibu bekerja yaitu nenek sebanyak 17 orang $(28,3 \%)$. (Tabel 4).

Tabel 5 Distribusi status membawa anak ke tempat kerja di Desa Batusuya Kecamatan Sindue Tumbusabora Kabupaten Donggala

\begin{tabular}{lcc}
\hline Variabel & $\boldsymbol{f}$ & $\mathbf{\%}$ \\
\hline $\begin{array}{l}\text { Membawa anak } \\
\text { ketempat kerja }\end{array}$ & & \\
$\quad$ Tidak & 51 & 85,0 \\
Ya & 9 & 15,0 \\
$\begin{array}{l}\text { Penjaga/pengasuh } \\
\text { anak saat ibu } \\
\text { bekerja }\end{array}$ & \\
$\quad$ Suami & 9 & 15,0 \\
Nenek & 17 & 28,3 \\
Tante & 16 & 26,7 \\
Pengasuh (baby \\
sitter)
\end{tabular}

Keberadaan ruang/bilik menyusui di tempat kerja menjadi salah satu hal yang dapat mendukung kegiatan menyusui di tempat kerja. Sebagian besar responden merasa tidak nyaman menyusui di tempat kerja sebanyak 50 orang $(83,3)$, sedangkan yang 
merasa nyaman sebanyak 10 orang $(16,7 \%)$.

Alasan tidak nyaman menyusui ditempat kerja yaitu belum menyediakan tempat yang khusus dan nyaman untuk ibu menyusu sebanyak 37 orang $(75,5 \%)$.

Tabel 5 Kenyamanan menyusui di tempat kerja di Desa Batusuya Kecamatan Sindue Tumbusabora Kabupaten Donggala

\begin{tabular}{|c|c|c|c|c|}
\hline \multirow{2}{*}{$\begin{array}{l}\begin{array}{l}\text { Alasan tidak } \\
\text { menyusui } \\
\text { kerja }\end{array} \\
\end{array}$} & \multicolumn{4}{|c|}{$\begin{array}{l}\text { Kenyamanan menyusui } \\
\text { ditempat kerja }\end{array}$} \\
\hline & Ya & $\%$ & Tidak & $\%$ \\
\hline $\begin{array}{l}\text { Belum menyediakan } \\
\text { tempat yang khusus dan } \\
\text { nyaman untuk ibu } \\
\text { menyusu }\end{array}$ & 4 & 6,6 & 37 & 61,6 \\
\hline $\begin{array}{l}\text { Repot dikarenakan } \\
\text { banyak pekerjaan dan } \\
\text { tidak merasa nyaman }\end{array}$ & 1 & 1,6 & 11 & 18,3 \\
\hline Menggangu pekerjaan & 2 & 3,3 & 1 & 1,6 \\
\hline $\begin{array}{l}\text { Ditempat kerja } \\
\text { dilarang untuk } \\
\text { membawa anak }\end{array}$ & 3 & 5 & 1 & 1,6 \\
\hline
\end{tabular}

Sumber: Data primer terolah,2020.

b. Cara penyimpanan ASI di Freezer adalah ASI yang sudah di perah disimpan dengan cara yang tepat supaya kualitasnya tetap terjaga sampi diberikan kepada bayi.

Berdasarkan tabel 6 diketahui bahwa dari 60 responden terlihat sebagian besar ibu tidak tahu cara menyimpan ASI di freezer pada saat ibu bekerja yaitu 56 orang $(93,3 \%)$. Cara ibu menyimpan ASI di freezer ada dua hasil yang sama dengan jawaban yang berbeda, jawaban pertama ASI dipompa disimpan diwadah tertutup lalu disimpan di dalam freezer pastikan wadah harus steril sebanyak 2 orang $(50,0 \%)$, jawaban yang kedua ASI dipompa terlebih dahulu disimpan ke gelas terus disimpan di freezer yaitu 2 orang $(50,0 \%)$.

Tabel 6 Distribusi cara penyimpanan ASI dalam freezer oleh ibu pekerja di Desa Batusuya Kecamatan Sindue Tumbusabora Kabupaten Donggala

\begin{tabular}{lcc}
\hline $\begin{array}{l}\text { Ibu tahu cara menyimpan } \\
\text { ASI di freezer saat ibu } \\
\text { bekerja }\end{array}$ & $\boldsymbol{f}$ & $\mathbf{\%}$ \\
\hline Tidak tahu & 56 & 93,3 \\
Tahu & 4 & 6,7 \\
Cara ibu menyimpan ASI & & \\
di freezer & & \\
$\quad$ ASI dipompa disimpan & 2 & 50,0 \\
$\quad$ diwadah tertutup lalu \\
$\quad$ disimpan didalam freezer \\
pastikan wadah harus \\
$\quad$ steril dan jaukan dari \\
$\quad$ jangkauan anak-anak \\
$\quad \begin{array}{l}\text { ASI dipompa terlebih } \\
\text { dahulu disimpan ke gelas }\end{array}$ \\
terus disimpan difreezer \\
\hline Sumber: Data primer terolah,2020. \\
\end{tabular}

\section{PEMBAHASAN}

Penelitian ini dilakukan di Desa Batusuya Kecamatan Sindue Tumbusabora Kabupaten Donggala dengan jumlah responden ibu pekerja yang mempunyai balita sebanyak 60 responden. Penelitian ini menggambarkan tentang bagaimana praktek pemberian ASI Ekslusif pada ibu pekerja dengan analisis yang digunakan yaitu analisis univatiat.

Berdasarkan hasil analisis univariat dari 60 responden ibu balita menunjukan bahwa sebagian besar tidak ASI Ekslusif yaitu sebanyak 51 anak $(85,0 \%)$, sedangkan yang ASI eksklusif hanya berjumlah 9 anak (15,0\%). Berdasarkan hasil dari wawancara bersama ibu yang menjadi penyebab tidak dapat memberikan ASI Ekslusif yaitu pada bagian puting payudara 
ibu mengalami lecet dan sebagian besar ASI tidak keluar sehingga kebanyakan ibu menggantikannya dengan susu formula. Adapun alasan lainnya yang menjadi penyebab sehingga ibu tidak dapat memberikan ASI Ekslusif yaitu karana status pekerjaan yang dimiliki ibu dan juga ada beberapa ibu yang tidak mau membawa anaknya ke tempat kerja, dikarenakan akan menggangu aktifitas di tempat ibu bekerja. Hal ini sejalan dengan penelitian yang dilakukan oleh (Mohanis, 2014). yang menyebutkan bahwa memberikan ASI Ekslusif kepada bayi sangat menguntungkan untuk tumbuh kembang bayi, namun masih banyak juga ibu-ibu dengan berbagai alasan salah satunya karena pekerjaan, sehingga tidak memberikan ASI Ekslusif pada bayinya yang membuat cakupan pemberian ASI Ekslusif tidak tercapai.

Berdasarkan penelitian lainnya yang menyatakan hal yang sama yaitu dikemukakan oleh (Danso, 2014). bahwa ibu yang memiliki status pekerjaan akan mengalami kesulitan dalam memberikan ASI Ekslusif karena harus membagi waktu dengan pekerjaannya, selain itu pengaruh dari anggota keluarga juga mempengaruhi praktek pemberian ASI Ekslusif. Dukungan keluarga terutama suami, orang tua atau mertua sangat penting dalam suksesnya menyusui.

Adapun juga hasil penelitian ini sesuai dengan penelitian (Anggania dkk 2018). yang mengatakan bahwa ada beberapa faktor yang dapat menyebabkan ibu tidak memberikan ASI
Ekslusif disebabkan yaitu pertama faktor pendidikan seseorang, maka semakin mudah untuk menerima informasi sehingga semakin banyak pula pengetahuan yang dimiliki. Berdasarkan penelitian yang telah dilakukan masih banyak ibu pekerja yang belum tahu cara menyimpan ASI di freezer, dikarenakan kurangnya membaca dan kurang memperoleh informasi dari petugas kesehatan yang berada Di Desa Batusuya.

Berdasarkan hasil penelitian yang telah dilakukan menunjukkan golongan umur responden ibu pekerja sebagian besar adalah umur 20 - 35 tahun. Umur akan menentukan perilaku dan sikap ibu dalam melakukan tindakan dalam pemberian ASI Ekslusif. Hal ini sejalan dengan penelitian yang dilakukan oleh (Tutuk dkk 2014). yang menyebutkan bahwa umur dapat melatar belakangi penentuan perilaku ibu pekerja dalam pemberian ASI Ekslusif pada bayi. Setiap kelompok usia akan mempunyai pandangan dan sikap yang berbeda dalam memberikan ASI Ekslusif pada bayi.

Pendidikan ibu pada penelitian ini menunjukkan sebagian besar ibu memiliki tingkat pendidikan menengah yaitu SMA dan sebagian besar pekerjaan ibu adalah wiraswasta. Seperti yang dikemukakan oleh (Tutuk dkk 2014). tingkatan pendidikan menengah yaitu SMA diperlukan untuk mendapat informasi misalnya hal-hal yang menunjang kesehatan sehingga dapat meningkatkan kualitas hidup dan mendaptkan pekerjaan yang lebih baik.. 
Penghasilan/bulan keluarga pada penelitian ini menjukan sebagian besar ibu memiliki pengasilan menurut < UMP Rp.2.303.711 yaitu sebanyak 58,3\%. Seperti yang dikemukakan oleh (Intan, 2014). faktor ekonomi berkaitan erat dengan konsumsi makanan atau dalam penyajian makanan keluarga khusunya dalam pemberian ASI. Keadaan umum ini dikarenakan rendahnya pendapatan yang mereka peroleh.

\section{KESIMPULAN DAN SARAN}

Dari hasil penelitian disimpulkan sebagian besar ibu pekerja tidak memberikan ASI eksklusif kepada bayinya, tidak tahu cara penyimpanan ASI di freezer. Disarankan kepada ibu balita untuk meningkatkan lagi pengetahuan tentang ASI ekslusif dan strategi tetap memberikan ASI meskipun bekerja di luar rumah.

\section{DAFTAR PUSTAKA}

1. Anggania, dkk. Hubungan Status Pekerjaan Ibu Dengan Pemberian Asi Ekslusif di Wilayah Kerja Puskesmas Kawangkoan. Universitas Sam Ratulangi Manado 2018.

2. Andriani, M dan Wirjatmadi, B. Peranan Gizi Dalam Siklus Kehidupan.Karena Prenada Media Group. Jakarta 2012.

3. Danso, J. Praktek ASI Ekslusif pada ibu pekerja. Universitas Negri Semarang 2014.
4. Dinas Kesehatan Kabupaten Donggala. Profil Kesehatan Kabupaten Donggala 2019.

5. Mohanis, W. Peran Petugas Kesehatan dan Status Pekerjaan Ibu dengan Pemberian Asi Ekslusif. J. Kesehatan Masyarakat 2014.

6. Mulyani S N. ASI dan Paduan Ibu Menyusui. Nuha Medika, Yogyakart 2013.

7. Muryunani, A. Inisiasi Menyusui Dini, ASI Ekslusif dan Manajemen Laktasi Trans Info Media. Jakarta 2012.

8. Ni'mah dan Nadhiroh, Faktor Yang Berhubungan Dengan Kejadian Stunting Pada Balita. Fakultas Kesehatan Masyarakat Universitas Airlagga. Surabaya 2015.

9. Profil Kesehatan Puskesmas Batusuya 2019.

10. Purwanti, SH. Konsep Penerapan ASI EKSLUSIF. Buku Kedokteran EGC. JAKARTA 2012.

11. Setyarini dan Mexitalia. Pengaruh Pemberian ASI Ekslusif dan Non Ekslusif Terhadap Mental dan Emosional Anak Usia 3-4 Tahun. Fakultas Kedokteran Universitas Penegoro. Semarang 2015.

12. Tutuk Sulistiyowati. Perilaku Ibu Bekerja dalam Memberikan ASI Ekslusif di Kelurahan Japanan Wilayah Kerja Puskesmas Kemlagimojokerto. Fakultas Kesehatan Masyarakat Universitas Airlagga Surabaya 2014. 